\title{
PENGARUH PENERAPAN METODE EDUTAINMENT DALAM PEMBELAJARAN TERHADAP HASIL BELAJAR IPS MURID SD KARTIKA XX-I
}

\author{
Nur Alfyfadhilah Rusydi ${ }^{1}$ \\ ${ }^{1}$ Prodi PGSD, STKIP Andi Matappa, Pangkep \\ Email : alfy.dhiela@gmail.com
}

\begin{abstract}
Metode Edutainment dalam pembelajaran berpengaruh terhadap hasil belajar IPS. Penelitian ini bertujuan untuk menjelaskan gambaran penerapan metode edutainment dalam pembelajaran pada murid SD Kartika XX-I Kecamatan Mamajang Kota Makassar, mengetahui gambaran hasil belajar IPS murid SD Kartika XX-I Kecamatan Mamajang Kota Makassar, menganalisis pengaruh penerapan metode edutainment dalam pembelajaran terhadap hasil belajar IPS murid SD Kartika XX-I. Jenis penelitian ini merupakan penelitian eksperimen yaitu true experiment design dengan bentuk desain Pretest-Posttest Control Group Design. Sampel pada penelitian ini terdiri dari 40 orang yang diperoleh melaui teknik pengambilan sampel adalah probability sampling dengan jenis teknik yaitu Two-Stage Random Sampling. Teknik analisis data hasil pada penelitian ini menggunakan 2 jenis statistik yaitu analisis statistik deskriptif dan analisis statistik inferensial yaitu uji-t. Hasil penelitian menunjukkan bahwa: (i) penerapan metode edutainment dalam pembelajaran oleh guru menunjukkan bahwa keterlaksanaan pembelajaran oleh guru dari pertemuan I sampai dengan pertemuan IV secara umum berada pada kategori baik, (ii) rata-rata hasil tes belajar IPS pada kedua kelompok sebelum perlakuan berada pada kategori kurang dan rata-rata hasil tes belajar IPS setelah perlakuan yaitu kelompok eksperimen berada pada kategori baik $(77,50)$ dan kelompok kontrol berada pada kategori kurang $(45,78)$, (iii) terdapat perbedaan hasil belajar IPS yang signifikan antara sebelum dan sesudah menerapkan metode edutainment dalam pembelajaran.
\end{abstract}

Kata kunci: penerapan metode edutainment, hasil belajar IPS.

\section{PENDAHULUAN}

Banyak sekolah-sekolah yang belum mampu menunjukkan khitahnya sebagai taman pendidikan sebagaimana yang disuarakan oleh Bapak Pendidikan Indonesia; Ki Hajar Dewantara. Salah satu asumsi bahwa sekolah ruang kelas sekarang menjadi penjara, guru serta proses pembelajaran menjadi momok yang menjenuhkan bagi murid.
Hal yang sering menjadi masalah di dalam kelas adalah seringkali proses pendidikan peserta didik di sekolah tidak sesuai dengan harapan dari tindakan mendidik itu sendiri. Pembelajaran yang cenderung kaku, bahkan ada yang penuh tekanan yang mengakibatkan ketegangan dalam proses pembelajaran. Menurut Dewey (2002:58):

$\begin{array}{lrr}\text { Semua prosedur ketat yang } \\ \text { sangat mengekang } & \begin{array}{r}\text { dan } \\ \text { membelenggu anak harus }\end{array}\end{array}$


dihilangkan apabila kita menginginkan suatu kesempatan baik bagi pertumbuhan pribadi dalam seluruh sumber intelektual dari kebebasan dan yang tanpanya tidak ada jaminan apapun bagi pertumbuhan normal yang sejati dan yang terus berkelanjutan.

Maka dari itu, untuk membuat proses belajar menjadi efektif adalah dengan menciptakan kondisi dan situasi yang nyaman dengan masuk ke dalam zona Alfa peserta didik.

Inti dari pada zona alfa adalah otak bekerja dengan rileks. Sehingga perlu dirancang proses pembelajaran yang dapat membuat peserta didik masuk dalam zona alfa baik saat memulai pembelajaran maupun dalam proses pembelajaran. Salah satu upaya yang dapat dilakukan dengan menyajikan halhal yang dapat menarik perhatian mereka seperti hiburan.

Memanfaatkan hiburan -baik bermain (hiburan aktif) atau pun media hiburan lainnya sebagai medium untuk belajar diharapkan dapat membantu tercapainya hasil pembelajaran yang lebih optimal. Pembelajaran tersebut dapat dilakukan dengan menerapkan metode pembelajaran yang disebut Edutainment. Dimana edutaiment merupakan proses pembelajaran yang mengkombinasi education dengan entertainment.

Manusia sebagai makhluk sosial tidak luput dari berbagai interaksi sosial, lahir dari kelompok kecil lalu kelak terjun dalam lingkup sosial yang lebih luas. Untuk itu diperlukan bekal dan proses belajar yang tepat agar anak mampu menunjukkan eksistensi dalam berkehidupan sosial serta memiliki kecerdasan sosial. Peran ilmu pengetahuan sosial dalam kehidupan sangat penting.
Pada kenyataannya, pendidikan IPS terutama di sekolah dasar yang merupakan salah satu tahap yang dianggap tepat menjadi landasan pendidikan dan pengetahuan sosial pada anak seringkali menjadi terkesampingkan. Hal itu dikarenakan pada proses pembelajaran, IPS selama ini dianggap pembelajaran yang membosankan, disajikan dalam proses yang juga membosankan dan penuh berbagai teori yang menuntut kita menghafal bukan memahami. Akhirnya muncul ketidaktertarikan peserta didik terhadap mata pelajaran IPS menyebabkan tidak tercapainya tujuan dan hasil belajar IPS yang diharapkan. Melalui metode Edutainment diharapkan pembelajaran IPS tidak lagi menjadi sekedar teori yang tidak berimplikasi pada kehidupan sosial anak secara konkret.

Berdasarkan uraian di atas yang merupakan kegelisahan peneliti dan juga sebagian pemerhati pendidikan maka peneliti mengangkat tesis yang berjudul "Pengaruh Penerapan Metode Edutainment dalam Pembelajaran Terhadap Hasil Belajar IPS di SD Kartika XX-I Kecamatan Mamajang Kota Makassar".

Berdasarkan uraian latar belakang maka dapat dirumuskan pertanyaan untuk penelitian sebagai berikut:

1. Bagaimana gambaran penerapan metode edutainment dalam pembelajaran pada murid di SD Kartika XX-I Kecamatan Mamajang Kota Makassar?

2. Bagaimana gambaran hasil belajar IPS SD Kartika XX-I Kecamatan Mamajang Kota Makassar?

3. Apakah ada pengaruh penerapan metode edutainment dalam pembelajaran terhadap hasil belajar IPS murid SD Kartika XX-I Kecamatan Mamajang Kota Makassar? 


\section{TINJAUAN PUSTAKA}

\section{A. Metode Edutainment dalam Pembelajaran}

Edutainment merupakan akronim dari kata education dan entertainment yang jika diterjemahkan ke dalam Bahasa Indonesia berarti pendidikan dan hiburan. Menurut Hamid (2011:17) "edutainment adalah pendidikan yang menghibur atau menyenangkan."

Lanjut Hamid mengemukakan:

Dari segi terminologi, edutainment adalah suatu proses pembelajaran yang di desain sedemikian rupa, sehingga muatan pendidikan dan hiburan bisa dikombinasikan secara harmonis untuk menciptakan pembelajaran yang menyenangkan.

Selanjutnya edutainment menurut Pangastuti (2014:60):

Dapat diartikan sebagai program pendidikan atau pelatihan yang dikemas dalam konsep hiburan sedemikian rupa, sehingga tiaptiap peserta didik hampir tidak menyadari bahwa mereka sebenarnya sedang diajak untuk belajar atau untuk memahami nilai-nilai (value) setiap individu.

Dalam perkembangannya edutainment lebih dikenal dalam dunia teknologi modern, sesuai dengan sebuah jurnal dimana Anikina dan Yamenko (2014) mengemukakan:

Perkembangan pesat teknologi menyediakan aktivitas baru yg menyenangkan, di samping memudahkan kita mendapat informasi dalam waktu sekejap. Sebagai tambahan, proses kognitif tidak diwajibkan dalam lingkungan formal (yg biasanya

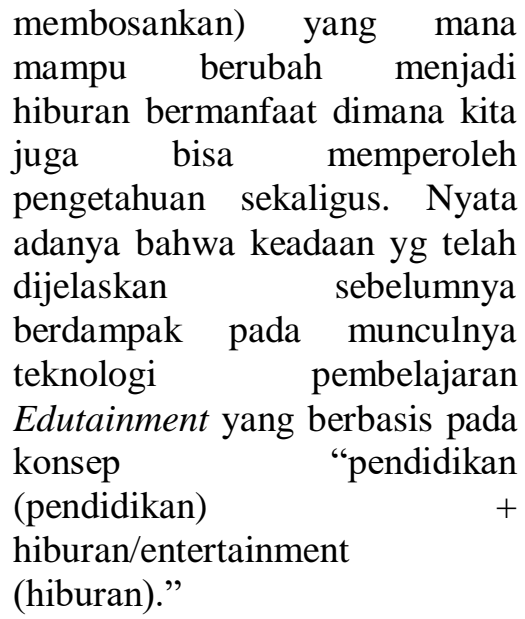

Edutainment dalam proses pembelajaran diterapkan dengan memenuhi (memperhatikan) aspek berikut (Hamruni; Pangasuti, 63:2014):

a. Memberi kemudahan dan suasana gembira

b. Menciptakan lingkungan belajar yang kondusif

c. Menarik minat

d. Menyajikan materi yang relevan

e. Melibatkan emosi positif dalam pembelajaran

f. Melibatkan semua indera dan pikiran

g. Menyesuaikan dengan tingkat kemampuan peserta didik

h. Memberi pengalaman sukses

i. Merayakan hasil

Berdasarkan uraian aspek-aspek penerapan metode edutainment dan gambaran praktek edutainment maka dapat dirumuskan langkah-langkah penerapan metode edutainment dalam pembelajaran adalah sebagai berikut:

1. Guru mengawali pembelajaran dengan memberikan ice breaking

2. Guru menyampaikan tujuan pelajaran dengan memberi gambaran secara kontekstual (apersepsi).

3. Guru menyampaikan pembelajaran dengan media entertainment yang telah disesuaikan dengan materi pelajaran. 
4. Guru menyajikan pembelajaran berbasis aktivitas (outdoor/indoor) melalui Lembar Kerja Murid (LKM).

5. Guru menutup pembelajaran dengan memberikan apresiasi atau reward pada siswa.

\section{B. Hasil Belajar}

Menurut Gredler (1986) dalam Khodijah (2014:49) menyatakan "belajar sebagai proses perolehan berbagai kompetensi, keterampilan, dan sikap (learning is the process by which human being acquire a vast variety of competencies, skill, and attitudes).

Lebih lanjut Suryabrata (2013:231) mengemukakan bahwa "menurut Crondbach belajar yang sebaik-baiknya adalah dengan mengalami; dan dalam mengalami itu si pelajar mempergunakan pancainderanya."

Dengan demikian, belajar merupakan kegiatan yang melibatkan proses berpikir dan merasakan melalui pengalaman (proses gabungan multiindra disertai kegiatan fisik secara aktif) dengan tujuan adanya perubahan tingkah laku dan perolehan berbagai aspek seperti kompetensi, pemahaman, keterampilan dan sikap.

Proses belajar yang dilakukan oleh individu ataupun kelompok tentunya memiliki dampak bagi kehidupan yang diistilahkan "hasil". Tujuan yang telah ditetapkan dalam pendidikan tersebut mengenai beberapa aspek, menurut Susanto (2013:5) "dapat dipahami tentang makna hasil belajar, yaitu perubahan-perubahan yang terjadi pada diri siswa, baik yang menyangkut aspek kognitif, afektif, dan psikomotorik sebagai hasil dari kegiatan belajar. Selanjutnya menurut Nawawi (tanpa tahun) dalam Brahim (2007:39) dalam Susanto (2013:5) menyatakan "hasil belajar dapat diartikan sebagai tingkat keberhasilan siswa dalam mempelajari materi pelajaran di sekolah yang dinyatakan dalam skor yang diperoleh dari hasil tes mengenai sejumlah materi pelajaran tertentu."

Jadi, hasil belajar merupakan suatu hasil yang diperoleh dari aktivitas pembelajaran baik aspek psikomotorik, afektif dan kognitif melalui instrument tertentu sesuai dengan tujuan yang ditetapkan.

Hasil belajar berkaitan dengan keberhasilan pembelajaran, menurut Arifin (2009:294) dalam Rachmah (2014:172) "keberhasilan pembelajaran dipengaruhi oleh beberapa faktor salah satunya adalah guru harus dapat melaksanakan pembelajaran, untuk itu ada prinsip-prinsipmtertentu dalam melaksanakan pembelajaran."

Sedangkan menurut Walisman (2007:158) dalam Susanto (2013:12) "Hasil belajar yang dicapai peserta didik merupakan hasil interaksi antara berbagai faktor yang mempengaruhi, baik faktor internal maupun faktor eksternal." Lebih lanjut Walisman (2007:158) dalam Susanto (2013:12) mengurai secara lebih terperinci faktor internal dan faktor eksternal.

Sehingga dapat disimpulkan bahwa ada beberapa faktor yang dapat mempengaruhi hasil belajar yaitu dari segi internal pebelajar seperti keinginan untuk belajar, ketekunan, motivasi, kondisi fisik dan sebagainya. Sedangkan dari segi eksternal faktor tersebut bisa berupa orangtua, sekolah, guru atau pun keadaan ekonomi keluarga.

\section{Ilmu Pengetahuan Sosial (IPS)}

Ilmu sosial merupakan ilmu yang berkaitan dengan kehidupan sosial manusia, menurut Alma, dkk (2010:3) "istilah studi sosial atau social studies 
diserap ke dalam bahasa Indonesia dengan istilah Ilmu Pengetahuan Social."

Pada dasarnya ilmu pengatahuan sosial menekankan pada pendidikan yang berkaitan hal-hal yang menyangkut kehidupan sosail dimana kita ketahui bahwa manusia menrupakan makhluk sosial, Rachmah (2014:52) mengemukakan "IPS adalah merupakan bahan pilihan yang sudah disederhanakan dan diorganisasikan secara ilmiah untuk kepentingan pendidikan."

Berdasarkan uraian di atas maka pernyataan Djahiri (1979) dalam Supardan (2015:14) semakin menegaskan bahwa:

IPS (social studies atau studi sosial) merupakan ilmu pengetahuan yang memadukan sejumlah konsep pilihan dari cabang-cabang ilmu pengetahuan sosial dan ilmu lainnya serta kemudian diolah berdasarkan prinsip pendidikan dan didaktik untuk dijadikan program pengajaran tingkat persekolahan.

Jadi, IPS merupakan perngorganisasian ilmu-ilmu sosial yang disederhanakan dan dikembangkan berdasarkan kondisi fisik dan realitas sosial yang ada dilingkungan peserta didik dengan harapan peserta didik dapat menjadi anggota masyarakat yang memiliki pengetahuan, sikap dan keterampilan sosial.

Jarolimek (1971) dalam Supardan (2015:13) merincikan tujuan ilmu pengetahuan sosial ke dalam beberapa aspek:

Tujuan sosial dikategorikan ke dalam tiga kelompok tujuan, yakni: (1) Understanding, yang berhubungan dengan pengetahuan dan kecerdasan (knowledge dan knowing); (2) attitudes, yang berhubungan dengan nilai-nilai, apresiasi, cita-cita, dan perasaan; (3) Skills, yang berhubungan dengan penggunaan dan pemakaian pembelajaran studi sosial dan kemampuan untuk memperoleh ilmu pengetahuan baru.

Visi pembelajaran IPS yang powerful sebagaimana yang dijelaskan oleh Brophy dan Aleman (2008:39-40) dalam Supardan (2015:53):

Pembelajaran social studies/IPS tersebut hendaknya menjadi pelajaran yang kuat dan kokoh (powerful) dengan berbasis pada pembelajaran yang bermakna (meaningful), integratif (intergrative), berbasis nilai (value-based), menantang (challenging), dan mengaktifkan (active) siswa belajar.

Dengan demikian, tujuan dari pembelajaran IPS adalah agar peserta didik memiliki kecakapan-kecakapan sosial; menjadi anggota masyarakat yang baik, memiliki kepekaan sosial dan kemampuan berpikir (menganalisis dan memecahkan persoalan sosial dalam kehidupan sehari-hari).

Mengenai ruang lingkup IPS tersebut Rachmah (2014:81) mengemukakan:

Ruang lingkup IPS tidak lain adalah kehidupan sosial manusia di masyarakat. Oleh karena itu, masyarakat inilah yang menjadi sumber utama IPS. Aspek kehidupan sosial yang kita pelajari, apakah itu hubungan sosial, ekonomi, budaya, kejiwaan, sejarah, geografi ataukah itu politik, bersumber dari masyarakat. 
Sedangkan menurut Depdiknas (2006) ruang lingkup mata pelajaran IPS SD meliputi aspek-aspek sebagai berikut:

1) Manusia, tempat dan lingkungan.

2) Waktu, keberlanjutan dan perubahan.

3) Sistem Sosial dan Budaya.

4) Perilaku Ekonomi dan Kesehjahteraan.

Dengan demikian dapat disimpulkan bahwa ruang lingkup IPS di sekolah dasar tidak lain merupakan hal-hal yang berkaitan dengan kehidupan sosial manusia yang meliputi tempat dan lingkungan, waktu, sistem sosial dan perilaku ekonomi.

Untuk melihat apa yang menjadi penanda ilmu pengetahuan sosial yang diperuntukkan pada jenjang sekolah dasar maka dapat ditelaah dari karakterisik IPS tersebut. Menurut Sapriya (2008:160) dalam Susanto (2013:159):

Pada jenjang sekolah dasar, pegorganisasian materi mata pelajaran IPS menganut pendekatan terpadu (integrated), artinya materi pelajaran dikembangkan dan disusun tidak mengacu pada disiplin ilmu yang terpisah melainkan mengacu pada aspek kehidupan nyata (factual/real) peserta didik sesuai dengan karakteristik usia, tingkat perkembangan berpikir, dan kebiasaan bersikap dan berperilakunya.

Maka dapat disimpulkan bahwa karakteristik IPS di sekolah dasar yakni adanya pengorganisasian materi ilmu sosial yang disederhanakan dan disajikan dengan penyesuaian untuk jenjang pendidikan sekolah dasar agar menarik minat peserta didik, mudah dipelajari dan mudah dimengerti oleh peserta didik di sekolah dasar.

Berdasarkan tinjauan pustaka maka dirumuskan hipotesis penelitian ini yaitu: "Ada pengaruh penerapan edutainment dalam pembelajaran terhadap hasil belajar IPS murid."

Kemudian skema kerangka pikir dari penelitian ini adalah sebagai berikut:

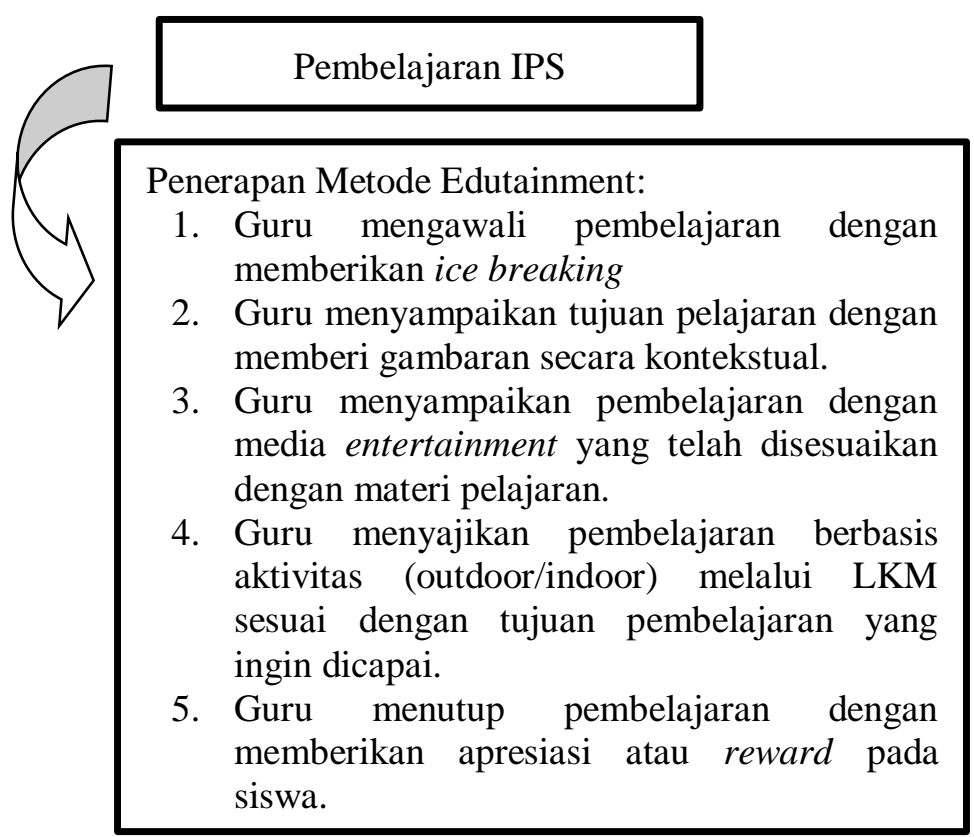

Gambar 2.1 Skema Kerangka Pikir Penelitian 


\section{METODE PENELITIAN}

Jenis penelitian yang digunakan adalah True Experimental Design dengan bentuk desain Pretest-Posttest Control Group Design. Penelitian True Experimental Design merupakan jenis penelitian yang menerapkan prosedur random pada partisipan untuk membentuk kelompok kontrol dan kelompok eksperimen.

Kelompok eksperimen akan diberi perlakuan pembelajaran IPS dengan menerapkan metode edutainment dan kelompok kontrol akan melakukan pembelajaran IPS tanpa metode edutaiment.

Dalam desain ini, dilakukan random sampling untuk membentuk kelas eksperimen dan kelas kontrol, kedua kelas ini kemudian diberikan tes awal (pretest) lalu untuk kelas eksperimen diberi perlakuan dengan menggunakan metode edutainment setelah itu kedua kelas diberikan tes akhir (posttest).

Pada penelitian ini terdapat dua variabel yaitu Variabel bebas atau independent variabel dalam penelitian ini adalah penerapan metode edutainment dalam pembelajaran (X) dan Variabel terikat atau dependent variabel dalam penelitian ini adalah hasil belajar IPS (Y).

Populasi dalam penelitian ini adalah murid SD Kartika XX-I Kecamatan Mamajang Kota Makassar yang terdiri dari 12 kelas dari 6 tingkatan. Dimana Sampel pada penelitian ini terdiri dari 40 orang yang diperoleh melaui teknik pengambilan sampel adalah probability sampling dengan jenis teknik yaitu TwoStage Random Sampling.

Teknik pengumpulan data adalah cara yang dilakukan untuk mengumpulkan data-data. Teknik pengumpulan data yang akan digunakan dalam penelitian ini adalah tes hasil belajar IPS dan lembar observasi.

Instrumen penelitian yang digunakan dalam penelitian ini di bagi menjadi dua kategori yaitu instrumen pengukuran berupa tes hasil belajar IPS dan lembar observasi kemudian instrumen pelakuan berupa Rencana Pelaksanaan Pembelajaran (RPP) dan lembar kegiatan murid (LKM).

Adapun hasil uji kelayakan instrumen terdiri dari analisis instrumen secara teoritis (validitas logik) "pada prinsipnya mencakup validasi isi, yang ditentukan utamanya atas dasar pertimbangan (judgment) dari para pakar" (Darmadi, 2014:159). Pada validitas logik penelitian ini dilakukan oleh dua orang pakar yang bertujuan untuk menunjukkan bahwa instrumen yang disusun benar-benar mewakili aspek yang diukur sehingga layak untuk digunakan. Kemudian analisis instrumen berdasarkan uji coba yang terdiri dari uji indeks kesukaran, uji daya pembeda butir soal, efektifitas pengecoh, uji validitas dan uji realibilitas.

Teknik analisis data hasil pada penelitian ini menggunakan 2 jenis statistik yaitu analisis statistik deskriptif dan analisis statistik inferensial. Analisis statistik deskriptif dimaksudkan untuk menganalisis data variabel kemudian mendeskripsikan atau menggambarkan data tanpa bermaksud membuat kesimpulan secara umum. Sedangkan Analisis data statistik inferensial dimaksudkan untuk menguji hipotesis dengan menggunakan uji-t. Namun demikian sebelum uji-t terlebih dahulu dilakukan uji prasyarat analisis yaitu uji normalitas dan uji homogenitas 


\section{HASIL PENELITIAN}

\section{A. Hasil Penelitian}

1. Gambaran Penerapan Metode Edutainment dalam Pembelajaran pada mata pelajaran IPS

Metode Edutainment merupakan metode yang mengasimilasi entertainment dan pendidikan. Dalam penelitian ini, metode ini kemudian di bawa dalam proses pembelajaran IPS.

Gambaran proses pembelajaran IPS dengan penerapan metode edutainment dapat dilihat berdasarkan uraian langkah-langkah yang telah disusun sesuai dengan aspek edutainment dalam pembelajaran, berkaitan dengan penelitian ini maka gambaran tersebut ditunjukkan melalui hasil observasi penerapan edutainment dalam pembelajaran yang dilakukan oleh praktikan (guru).

Berdasarkan dari data yang diperoleh selama penelitian maka klasifikasi keterlaksanaan pembelajaran dapat dilihat pada tabel 4.1 berikut.

\section{Tabel 4.1 Kualifikasi Data Hasil Keterlaksanaan Pembelajaran di Kelas Eksperimen}

\begin{tabular}{|c|c|}
\hline Pertemuan & Kualifikasi \\
\hline Pertemuan I & Cukup \\
\hline Pertemuan II & Baik \\
\hline Pertemuan III & Baik \\
\hline Pertemuan IV & Sangat Baik \\
\hline Rata-Rata & Baik \\
\hline
\end{tabular}

2. Gambaran Hasil Belajar Murid di Kelas IV SD Kartika XX-I Makassar

Hasil belajar murid diukur menggunakan instrumen berupa tes pilihan ganda yang berjumlah tiga puluh dua item pernyataan. Adapun gambaran hasil belajar siswa pada kelas eksperimen dan kelas kontrol berdasarkan tes hasil belajar siswa adalah sebagai berikut:

Tabel 4.2 Rekapitulasi Hasil Belajar Murid

\begin{tabular}{ccccc}
\hline \multicolumn{2}{c}{ Kelas Kontrol } & & \multicolumn{2}{c}{ Kelas Eksperimen } \\
Sebelum & Setelah & & Sebelum & Setelah \\
\hline 20 & 20 & Ukuran sampel & 20 & 20 \\
42,65 & 45,95 & Mean & 40,55 & 77,50 \\
6,06 & 5,44 & Standar deviasi & 7,08 & 6,06 \\
31 & 38 & Nilai tertinggi & 28 & 66 \\
53 & 56 & Nilai terendah & 53 & 88 \\
\hline
\end{tabular}

Sumber : Data Hasil Penelitian Tahun 2016 
Tabel 4.3. Distribusi Frekuensi Tingkat Kemampuan Hasil Belajar Murid Sebelum dan Sesudah Perlakuan

\begin{tabular}{|c|c|c|c|c|c|c|c|c|}
\hline \multicolumn{4}{|c|}{ Kelompok Eksperimen } & \multirow{3}{*}{$\begin{array}{c}\text { Rentangan } \\
\text { Nilai/ } \\
\text { Kategori }\end{array}$} & \multicolumn{4}{|c|}{ Kelompok Kontrol } \\
\hline \multicolumn{2}{|c|}{ Sebelum } & \multicolumn{2}{|c|}{ Setelah } & & \multicolumn{2}{|c|}{ Sebelum } & \multicolumn{2}{|c|}{ Setelah } \\
\hline $\mathbf{F}$ & $\%$ & $\mathbf{F}$ & $\%$ & & $\mathbf{F}$ & $\%$ & $\mathbf{F}$ & $\%$ \\
\hline 0 & 0 & 7 & 35 & $\begin{array}{c}81-100 \\
\text { Sangat Baik }\end{array}$ & 0 & 0 & 0 & 0 \\
\hline 0 & 0 & 13 & 65 & $\begin{array}{c}61-80 \\
\text { Baik }\end{array}$ & 0 & 0 & 0 & 0 \\
\hline 11 & 55 & 0 & 0 & $\begin{array}{l}41-60 \\
\text { Cukup }\end{array}$ & 15 & 75 & 18 & 90 \\
\hline 9 & 45 & 0 & 0 & $\begin{array}{l}21-40 \\
\text { Kurang } \\
\end{array}$ & 5 & 25 & 2 & 10 \\
\hline 0 & 0 & 0 & 0 & $\begin{array}{c}0-20 \\
\text { Sangat Kurang }\end{array}$ & 0 & 0 & 0 & 0 \\
\hline 20 & 100 & 20 & 100 & $\sum$ & 20 & 100 & 20 & 100 \\
\hline
\end{tabular}

3. Pengaruh penerapan metode edutainment dalam pembelajaran terhadap hasil belajar IPS

\section{a. Uji Paired Sample Test}

Uji t (paired Sample test) untuk mengetahui sampai sejauh mana perbedaan hasil belajar IPS murid sebelum dan sesudah pembelajaran dengan menggunakan metode edutainment. Adapun hasil dari uji $\mathrm{t}$ dapat disajikan sebagai berikut.

Tabel 4.11 Uji Paired Samples Test Kelas Eksperimen

\begin{tabular}{|c|c|c|}
\hline \multicolumn{3}{|c|}{ Sebelum dan Sesudah Perlakuan } \\
\hline Mean & Sig-2 Tailed & Keterangan \\
\hline 36,95 & 0,000 & Signifikan \\
& & $(0,000<0,05)$ \\
\hline
\end{tabular}

Tabel 4.5 Uji Paired Samples Test Kelas Kontrol

\begin{tabular}{|c|c|c|}
\hline \multicolumn{3}{|c|}{ Sebelum dan Sesudah Perlakuan } \\
\hline Mean & Sig-2 Tailed & Keterangan \\
\hline 33,30 & 0,006 & Tidak Signifikan \\
& & $(0,006>0,05)$ \\
\hline
\end{tabular}

\section{b. Uji Independent Sample Test}

Uji independent sample test digunakan untuk melihat keefektifan penerapan metode edutainment dalam pembelajaran tehadap hasil belajar IPS murid yaitu dapat diketahui dengan membandingkan antara tes setelah perlakuan (posttest) pada kelas eksperimen dan kelas kontrol. 
c. Tabel 4.6 Uji Independent Samples Test sebelum perlakuan kelas eksperimen dan kelas kontrol

\begin{tabular}{|c|c|c|}
\hline \multicolumn{3}{|c|}{ Sebelum Perlakuan Kelas Eksperimen dan Kelas kontrol } \\
\hline Mean different & Sig-2 Tailed & Keterangan \\
\hline 2,10 & 0,320 & Tidak Signifikan \\
& & $(0,320>0,05)$ \\
\hline
\end{tabular}

\section{d. Tabel 4.7 Uji Independent Samples Setelah perlakuan kelas Eksperimen dan} Kontrol

\begin{tabular}{|c|c|c|}
\hline \multicolumn{3}{|c|}{ Setelah Perlakuan Kelas Eksperimen dan Kelas kontrol } \\
\hline Mean difference & Sig-2 Tailed & Keterangan \\
\hline 31,5 & 0,000 & Signifikan \\
& & $(0,000<0,05)$ \\
\hline
\end{tabular}

\section{B. Pembahasan Hasil Penelitian}

1. Gambaran Penerapan Metode Edutainment dalam Pembelajaran pada mata pelajaran IPS

Penerapan metode edutainment dalam pembelajaran pada mata pelajaran IPS pada umumnya berjalan dengan baik. Selain karena langkah-langkah yang menitik beratkan pada hiburan, komunikasi yang harmonis antara guru dan murid pun terbangun dalam proses pembelajaran berkat penerapan metode edutainment. Hal ini dikarenakan metode edutainment mampu mendorong emosi positif murid dan semangat belajarnya. Menurut Meier (2002:85) "emosi, sebagaimana dibenarkan oleh penelitian dan akal sehat, berpengaruh pada kualitas dan kuantitas belajar."

Penelitian ini terbukti memberikan pembelajaran yang sangat menyenangkan dan peningkatan hasil belajar jika dibandingkan dengan kelas yang diajar tanpa menggunakan metode edutainment.

2. Hasil Belajar IPS Sebelum dan Sesudah Menggunakan Metode Edutainment dalam Pembelajaran.
Berdasarkan data yang diperoleh dari hasil penelitian dapat diketahui bahwa penerapan metode edutainment dalam pembelajaran dapat mempengaruhi hasil belajar IPS murid. Hal ini disebebkan oleh antusiasme dan fokus murid serta nyamannya proses pembelajaran membuat murid memperhatikan setiap sesi pembelajaran yang terjadi selama proses pembelajaran berlangsung. Murid yang merasa senang dalam belajar akan aktif mengikuti proses belajar dan hasil penelitian menunjukkan terjadinya perubahan hasil belajar murid di kelas.

\section{Pengaruh penerapan metode edutainment dalam pembelajaran terhadap hasil belajar IPS}

Berdasarkan hasil penelitian, penerapan metode edutainment berpengaruh secara signifikan terhadap hasil belajar IPS dibandingkan dengan pembelajaran tanpa menggunakan metode edutainment. Pengujian skor hasil belajar menggunakan uji $\mathrm{t}$ (independent samples test) memberikan kesimpulan bahwa hasil belajar IPS murid yang mendapat pembelajaran dengan metode edutainment lebih baik daripada tanpa menggunakan metode edutainment. Peningkatan ini mengindikasikan bahwa pembelajaran yang diimplementasikan, 


\section{DAFTAR PUSTAKA}

Alma, Buchari., dkk. 2010. Pembelajaran Studi Sosial. Bandung: Alfabeta.

Anderson, Lorin W dan Krathwohl, David R. 2014. Kerangka Landasan Untuk Pembelajaran, Pengajaran, dan Asesmen. Yogyakarta:Pustaka Pelajar.

Andriono, dkk. 2006. Sukses Melejitkan Potensi Anak Didik. Bandung: Mizan Learning Center (MLC).

Anikina, Oksana V and Yakimenko, Elena V. 2014. Edutainment as a modern technology of education. Russia: National Research Tomsk Polytechnic University.

Anitah W, Sri, dkk. 2008. Strategi Pembelajaran di SD. Jakarta:Universitas Terbuka.

Asape, Nuralim. 2001. Konsep Dasar Ekonomi dalam Mata Pelajaran IPS. Direktorat Jenderal Pendidikan Dasar dan Menengah: BPG Ujung Pandang.

Asfandiyar, Andi Yudha. 2009. Kenapa Guru Harus Kreatif?. Bandung: DAR! Mizan.

Beetlestone, Florence. 2013. Creative Learning. Bandung:Nusamedia.

Chan Sherman, 2007. Edutainment. (http://etec.ctlt.ubc.ca/510wiki/ Edutainment, diakses 30 April 2016).

Chatib, Munif. 2011. Gurunya Manusia; Menjadikan Semua Anak Istimewa dan Semua Anak Juara. Bandung: Kaifa.

Darmadi, Hamid. 2014. Metode Penelitian Pendidikan dan Sosial. Bandung: Alfabeta

DePorter, Bobbi \& Hernacki, Mike. 2009. Quantum Learning. Bandung: Kaifa

Dewantara, Ki Hajar. 1977. Pendidikan; Bagian Pertama. Yogyakarta:
Majelis Luhur Persatuan Taman Siswa.

Dewey, John. 2002. Pengalaman dan Pendidikan. Yogyakarta: Kepel Press.

Direktorat Jenderal Pendidikan Islam. 2007. Kumpulan UndangUndang dan Peraturan Pemerintah RI Tentang Pendidikan. Jakarta: Departemen Agama RI.

Fahreena. Tanpa Tahun. Edutainment. (https://fahreena.wordpress.com/ artikel/edutainment/, diakses 29 April 2016).

Freire, Paulo. 2013. Pendidikan Kaum Tertindas (Pedagody of The Oppressed). Jakarta: LP3ES.

Ghufron, Nur M \& Risnawati, Rini. 2010. Gaya Belajar Kajian Teoritik. Yogyakarta: Pustaka Pelajar.

Given, Barabara K. 2007. Brain-Based Teaching. Bandung: Kaifa.

Goleman, Daniel. 1996. Emotional Intelegence. Jakarta: Gramedia Pustaka Utama.

Hamalik, Oemar. 2001. Proses Belajar Mengajar. Jakarta: Bumi Aksara.

Hamid, Soleh. 2011. Metode Edutainment. Jogjakarta: Diva Press.

Hergenhan, B.R. dan Olson, Matthew H. 2008. Theories Of Learning. Jakarta: Kencana.

Huiyang, Lei and Jianfeng, Ren. 2011. Review of Edutainment and Flash in the Field of Educational. International Journal of Information and Education Technology, Vol. 1, No. 4, October 2011.

Hurlock, Elizabeth B. 2012. Psikologi Perkembangan. Jakarta:Erlangga.

Khodijah, Nyayu. 2014. Psikologi Pendidikan. Jakarta: Raja Grafindo Persada.

Jensen, Eric. 2008. Brain-Based Learning Edisi Revisi. Yogyakarta: Pustaka Pelajar. 
Magic, Win Com. Tanpa tahun. Apa itu edutainment.

(http://www.wincompmagic.co m/apa-itu-edutainment/, diakses 30 April 2016).

Meier, Dave. 2002. The Accelerated Learning Handbook. Bandung: Kaifa.

Muhadjir, Noeng. 2011. Psikologi Perkembangan Karakter. Yogyakarta: Rake Sarasin.

Muhammad, As'adi. 2010. Miliaran Keluarbiasaan Otak Kita. Jogjakarta: FlashBooks.

Olson, Matthew H dan Hergenhahn, B. R. 2008. Theories of Learning (Edisi Ketujuh). Jakarta: Kencana.

Omrod, E Jeanne. 2009. Psikologi Pendidikan. Jakarta: Erlangga.

Pangastuti, Ratna. 2014. Edutainment PAUD. Yogyakarta: Pustaka Pelajar.

Prashing, Barbara. 2007. The Power of Learning Style. Bandung: Kaifa.

Purwanto, Setyoadi. 2014. Menggali Prinsip Edutainment dalam Teori Quantum Learning. (http://adikitana.com/article/150 504/prinsip-edutainment.html, diakses, 30 April 2016).

Rachmah, Huriah. 2014. Pengembangan Profesi Pendidikan IPS. Bandung: Alfabeta.

Rakhmat, Jalaluddin. 2010. Belajar Cerdas Belajar Berbasiskan Otak. Bandung: Kaifa.

Riduwan. 2014. Metode dan Teknik Menyusun Tesis. Bandung: Alfabeta.

Ruslan. 2009. Validitas Isi. Buletin Pa'buritta. No. X. Tahun IV. September

Sadono, Tri. 2013. TaksonomiTaksonomi Pembelajaran. (http://trigurumetri.blogspot.co m/2013/08/taksonomitaksonomi-pembelajaran.html, diakses 29 April 2016)
Sanjaya, Wina. 2011. Kurikulum dan Pembelajaran. Jakarta: Kencana.

Schunk, Dale H. 2012. Learning Theories An Educational Perspective. Yogyakarta: Pustaka Pelajar

Setiadi, Andi. 2014. Rahasia Cara Belajar Einstein. Jogjakarta:Diva Press.

Silberman. Mel. 2001. Active Learning; 101 Strategi Pembelajaran Aktif. Yogyakarta: Yappendis.

Siregar, Eveline dan Nara Hartini. 2010. Teori Belajar dan Pembelajaran. Bogor: Ghalia Indonesia.

Sudjana, N. 2005. Penilaian Hasil Proses Belajar Mengajar. Bandung: PT. Remaja Rosdakarya.

Sudijono, Anas. 2009. Pengantar

Evaluasi Pendidikan. Jakarta: Rajawali

Pers.

Sugiyono. 2009. Metode Penelitian Kuantitatif Kualitatif dan $R \& D$. Bandung: Alfabeta.

- 2015. Metode Penelitian Pendidikan. Bandung: Alfabeta.

Supardan, Dadang. 2015. Pembelajaran Ilmu Pengetahuan Sosial Persfektif Filosofi dan Kurikulum. Jakarta: Bumi Aksara.

Suryabrata, Sumadi. 2013. Psikologi Pendidikan. Jakarta:Rajawali Pers.

Susanto, Ahmad. 2013. Teori Belajar dan Pembelajaran di Sekolah Dasar. Jakarta:Kencana.

Syah, Muhibbin. 2000. Psikologi Pendidikan dengan Pendekatan Baru (Revisi). Bandung: Remaja Rosdakarya.

Thoyibah, Nura'inun dkk. 2015. Meningkatkan Rasa Percaya Diri Anak Usia Dini Melalui Metode Edutainment. Bandung: Antologi UPI Volume Edisi No. Juni. 
Wade, Carole \& Tavris, Carol. 2007.

Psikologi Edisi Kesembilan.

Jakarta: Erlangga.

Winataputra, Udin S, dkk. 2011.

Pembaruan dalam

Pembelajaran di SD.

Jakarta:Universitas Terbuka.

Yamin, Martinis. 2012. Orientasi Baru

Ilmu Pendidikan. Jakarta:

Referensi. 